\title{
PERTANGGUNGJAWABAN HUKUM TERHADAP NOTARIS YANG MEMBUKA KANTOR CABANG ATAS NAMA SENDIRI (PUTUSAN NOMOR : 2/PTS/Mj.PWN.DKIJakarta/xi/2017)
}

\section{Febry Yanti}

(Mahasiswi Program S1 Fakultas Hukum Universitas Tarumanagara)

(E-mail: febryantiihartonooo@gmail.com)

\section{Gunawan Djajaputra}

(Corresponding Author)

(Dosen Fakultas Hukum Universitas Tarumanagara, Meraih Gelar Sarjana Hukum dari Fakultas

Hukum Universitas Indonesia, Magister Hukum dari Fakultas Hukum Universitas Indonesia, dan

Doktor Hukum dari Fakultas Hukum Universitas Indonesia)

(E-mail: Gunjapp62@yahoo.com )

\begin{abstract}
Indonesia is a country that adheres to the legal system. The role of the notary is very important in Indonesia. Notaries act as public officials in providing legal services to the public. Notaries are public officials who have the authority to make authentic deeds. A notary position is a public or public position because a notary is appointed and dismissed by the government. Notaries are prohibited from opening more than one notary office because notaries can only open one notary office. But in reality there is a notary who opens a branch office. How the accountability and position of the notary who establishes a branch office on its own behalf is a problem discussed. The research method used is normative legal research is to find the truth of coherence, namely the rule of law in accordance with legal principles. sourced from primary data and secondary data as other supporting data which are analyzed quantitatively. The results of the study explained that the West Jakarta Regional Supervisory Board found that there was a notary office with 2 signboards in the West Jakarta area that had a notary office named Notary Netty Maria Machdar. So that Netty Maria Machdar was found guilty and the position of the notary became hanging due to the absence of a further verdict because it was only proposed to be honorably dismissed by the Regional Supervisory Board so that in this case Netty Maria Machdar was found guilty and obliged to replace the loss but because there was no further verdict. Notary Netty Maria Machdar can still use her rights as a legitimate Notary. Notary Netty Maria Machdar also violated the Indonesian Notary Association Code of Ethics.
\end{abstract}

Keywords : Branch Offices, Notaries, Notary Responsibilities

\section{PENDAHULUAN}

\section{A. Latar Belakang}


Negaara Kesatuan Republiik Indonesiia (NKRI) yang memiliki kedaulatann beraada ditangaan rakyatt dan diilaksanakan menurut UUD. Di Indonesia notariis mempunyaii peranaan yang sangat pentiing dalam hukum. sehingga sangat dibutuhkan oleh masyarakat di Indonesia. Notariis merupakan pejabat umum yang memiliki wewenang untuk membuatkan aktaa otentiik sejauh pembuatan akta tertentu tidak dikhususkan bagu pejabat umum lainnya. Akta yang dibuat dihadapan notaris merupakan bukti otentik, bukti paling sempurna, dengan segala akibatnya. ${ }^{1}$

Jabatan notariis adalah jabataan umm atau publiik karena notariis diiangkat dan diberhentiikan oleh pemeriintah. Notariis mnjalankan tgas ngara dan aktta yng diibuat yaiitu aslii akta (minuta) adlah mrupakan dokmen negarra. Pjabat umuum adlah pjabat yng diiangkat dan diiberhentikan oleh keukuasaan umumm (pemeriintah) dan diiberi wwenang srta kewajiiban untk melayanii publiik dlam halhal ertentu, Karena iitu iia iikut mlaksanakan kewiibawaan pemeriintah. ${ }^{2}$

Dlam pngertian Notariis, tersirat bawa Notariis berenang utuk mmbuat aktta otentiik, hnya apabiila hl iitu diikenhendaki atau diiminta oleh yang berkepentiingan, hal man beirarti bhwa notariis tdak beirwenang membuatt aktta otentiik scara jbatan (ambtshalve). Weenang Notariis diinyatakan dngan prkataan-perkataan "mengenaii semua prbuatan, perjanjiian, dan ktetapan". 3 Wewnang Notariis meliputi 4 hal, yaiitu ${ }^{4}$ :

1. Notariis hrus berweanang spanjang yang mnyangkut akta yang diibuat iitu;

2. Notariis hrus brwenang seepanjang mengenaii orng-ortang untk kepentiingan siiapa aktta iitu dibiuat;

3. Notariis hrus brwenang seepanjang mengenaii tmpat, diimana aktta diibuat. 4. Notariis hrus berwnang seepanjang mengenaii waktuu pmbuatan aktta iitu.

\footnotetext{
${ }^{1)}$ A. Kohar, Notaris Dalam Praktek Hukum. (Bandung: Alumni, 1983), hal. 64.

2) R. Soesanto, Tugas, Kewajiban, dan Hak-Hak Notaris, Wakil Notaris. (Jakarta: Pradnya Paramita, 1982), hal. 75.

${ }^{3)}$ G.H.S. Lumban Tobing., Peraturan Jabatan Notaris. (Jakarta: Ind, Hill-co, 1990), hal. 39.

4) Ibid., hal. 49.
} 
Pada Psal 15 Ayat (1) Undaang-Undaang Nomlor 2 htahun 2014 tntang Jabattan Notairis. Notariis berwnang mmbuat atkta otentiik mengenaii smua perbuattan, perjanjiian, dan pnetapan yng diiharuskan oleh praturan peruundang-undaangan dan/atau yng dikehendakii olh yng berkepentiingan untk diinyatakan dlam aktta otentiik, menjamiin kepastiian tnggal pmbuatan aktta, menyiimpan aktta, memberiikan groosse, salinn dan kutiipan aktta, smuanya iitu spanjang pmbuatan aktta itiu tidiak jga diugaskan atau diikecualikan kpada pjabat laiin atau orng lain yng dtetapkan olh undanigundiang.

Setiap notaris memiliki wwenang yang telah dijelaskan pada pasal tersebut ditegaskan bahwa wewenangan notaris adalah membuatt aktta, bkan membuatt srat, sepertii suat kusa mebebankan hakk tnggungan atau mmbuat srat laiin, sepertii Srat Keerangan Wariis (SKW). Ada bberapa aktta otentiik yang merpakan wwenang notariis dan juga menjadii wwenang pjabat atau instansii laini, yaiitu: Aktta pngakuan anakk dii luarr kwin (Psal 281 bw), Aktta beriita acra tntang kelalaiian pjabat menyiimpan hiipotik (Psal 1227 bw), Aktta beriita acra tntang penwaran pmbayaran tunaii dan konsiinyasi (Psal 1405 dan 1406 bw). ${ }^{5}$

Selanjutnya menurut pasal tersebut pembuatan akta yang disertai oleh kode etik notaris menurut Liliana Tedjosaputro mengatakan bahwa "kode etk notairis adlah tntunan, bimibingan, bimibingan atau pedoan mral autau kesusiilaan notariis baiik slaku pribadii mauupun pjabat umum yng diiangkat pemeriintah dlam rngka pemberiian playanan umum, khsusnya dlam biidang pmbuatan aktta". ${ }^{6}$ Kde etiik notariis mmuat unsurr materiial tntang kewajiiban, lrangan, pengcualian dan sanksii yng akn diijatuhkan apabiila terbuktii sorang notariis melnggar kodee etikkk.

\footnotetext{
5) Habib Adjie, Hukum Notaris Indoensia Tafsir Tematik Terhadap UU No. 30 Tahun 2004 Tentang Jabatan Noataris. (Bandung: PT Refika Aditama, 2008), hal. 78 dan 79.

6) Liliana Tedjosaputro, Etika Profesi Notaris Dalam Penegakan Hukum Pidana. (Yogyakarta: Bayu Grafika, 1995), hal. 9.
} 
Salah satu larangan bagi notaris ada di dalam Pasal 19 mengatakan bahwa ${ }^{7}$ : Notariis wajiib mempunyaii hnya satuu kntor, yaiitu dii tmpat kdudukannya; Tmpat kdudukan notariis sebagaii Pjabat Pmbuat Aktta Tnah wajibi mengiikuti tmpat kdudukan notariis; Notariis tiidak brwenang scara bertrut-turutt dngan ttap meinjalankan jaibatan dii luiar teimpat keidudukannya; Noitaris yaing melianggar kietentuan sbagaimana dmaksud paida ayiat (2) dpat diikenai sanksii beriupa: Peiringatan tertuilis, Peimberhentian seimentara, Pemberhentiian dngan ormat; atau Pembeirhentian dnegan tdak hormtat.

Setiiap notairis jga harus mematuhii setiiap perturan yng tlah diibuat olh pemeriintah dan tdak mlanggar kodee etiik notariis. Sehiingga deingan adianya laraingan ini diharapkan notaris dapt bertiindak amainah, jiujur, saiksama, mandiiri, tiidak berpiihak, dan mnjaga kepentiingan piihak yng terkaiit daliam perbuatian huikum.

Notariis yang membuka kantor notaris lebih dari satu tidak diperbolehkan sebagiiaimana yaiing telahi diatur dalam Undng-Undiang Nomior 2 Taihun 2014 tntang Jabiatan Notariis. iSehingga apabila notaris tersbut ketahuan membuka kantor notiaris lebih dari satu maka notiaris tersebut dpat diknakan sanksii yang tlah diiatur olh pemerintah.

Dalam kasus yang penulis angkat dinyatakan bahwa adanya pejabat notariis yng mlanggar kodee etiik notaris, haal ini bermula dengan terlapor bernama Netty Maria Machdar yang membuka kantor cabang yang dilakukan oleh notaris pengganti bernama Jonni karena ia telah mendapat Surat Keputusan Menteri Hukum dan HAM Republik Indonesia, sebagai notaris pengganti, maka menurut professor $\mathrm{x}$ ia berhak membuat papan nama sendiri.

Berdasarkan uraian tersebut diangkatlah judul penulisan ini "Pertanggungjawaban Hukum Notaris Yang Mendirikan Kantor Cabang Atas Nama Sendiri (Putusan Nomor: 2/PTS/Mj.PWN.Prov. DKIJakarta/XI/2017 )”.

\footnotetext{
${ }^{7)}$ Indonesia, Undang-undang Nomor 2 Tahun 2014 tentang Jabatan Notaris. Pasal 19
} 


\section{B. Permasalahan}

1. Bagaimanakah pertanggungjawaban dan kedudukan notaris yang mendirikan kantor cabang atas nama sendiri (Putusan Noimor: 2/PTiiS/Mj.PWiiN.Prov. DKIJakarta/XI/2017) ?

\section{Metode Penelitiaan}

\section{Sifat Penelitiaan}

Sifat penelitiian inii mnggunakan pnelitian hukm normatiif. Peneliitian hukm normatiif adalah satu pross untk menmukan doktriin-doktriin hkum guna menjawab isu hukum yang dihadapi. ${ }^{8}$ Peneliitian hkum (Legal Research) adlah mnemukan kbenaran koherensii, yaiitu adkah atran hukum sesuaii dngan prinsiip hkum. Srta tiindakan sseorang sesuaii dngan norma hkum atau priinsip hukum. ${ }^{9}$

\section{Jenis dan Sumber Data}

Data yng digiunakan dlam peneliitian hkum inii dpat diibedakan menjadii:

a. Bahaan Hukium Pirimer

Bahian Hukium Prmer adaah bahain huikum mengkat, ying terdiri dari:

1) Kitaib Unidang-Undiang Hukium Peridata

2) Unidang-Undiang Nomior 2 Taihun 2014 teintang Prubahan UndngUndaing Niomor 30 Taihun 2004 tntang Jbatan Notariis

3) Kodee Etiik Ikiatan Notariis Inidonesia

b. Bhan Hukum Sekuinder

Bahain Hukuim Sekiunder brupa smua publiikasi tntang hukium yng bukain meupakan dkumen-dokuen resmii, pubilikasi teintang huikum antara lain ${ }^{10}$ Buk-buku teks, Kaimus-kamus hukium, Juirnal-jurinal huikum, Koimentar-koimentar atias piutusan piengadilan.

8) Peter Mahmud Marzuki, Penelitian Hukum, Cetakan ke-11, (Jakarta: Kencana, 2011), hal. 35.

9) Peter Mahmud Marzuki, Penelitian Hukum Edisi Revisi, (Jakarta: Kencana Preneda Media Group, 2013), hal. 181.

${ }^{10)}$ Peter Mahmud Marzuki, Op.Cit, hal. 141-142. 
c. Bahan Non Hukum ${ }^{11}$ : Laporan-laporan penelitian non-hukum, Jurnaljurnal non-hukum sepanjang masih relevan, Kamuis Beisar Bahiasa Indoinesia.

\section{Teknik Pengumpulan Dara}

Dalm penelitian hukum ini, tekniik penumpulan dta yang digunakan oleh peneliti adalah pengumpulan data melalui Undang-Undang (Statue Approach) dan studi kasus. Pengumpulan data melalui Undang-Undang adalah pengumpulan data yanig diakukan dngan meneilaah seimua UndagUndng dan regulasii yng bersangkutan paiut degan isui hukumi yanig sediang diitangani. ${ }^{12}$ Pengumpulan data melalui Undang-Undang ini perlu memahami mengenai Jabatan Notaris, serta doktrin-doktrin yang mengacu pada isu hukum yang ditelaah. Stuidi kaisus meriupakan suiatu stiudi terihadap kaisus teirtentu dairi bierbagai asipek huiikum. ${ }^{13)}$

\section{Teknik Pengolahan Data}

Teknik pengolahan data yang penelitian hukum ini gunakan adalah teknik deskriptif analitis, analisis diilakukan dngan caira analiisis kalitatif. Analisis kualitatif meriupakan anlisis daita yaing tiidak mengigunakan anigka, meilainkan memiberikan gaimbaran-giambaran (deskripsii) deingan katia-kata atas teimuan-teimuan, dn kareinanya ia leih mengutamakn mtu/kualiitas darii dta dan bukain kuaintitas. ${ }^{14}$

\section{Teknik Analisis Data}

Teknik analisis data menggunakan cara deduktif. "Teknik analisis deduktif menjlaskan suatdu hadl yandg befrsifat umumh kemujdian menajriknya mejnjadi kejsimpulan yanjg lebih jkhusus". ${ }^{15)}$ Teknik analisis

11) Ibid., hal. 143

12) Ibid., hal. 93.

${ }^{13)}$ Peter Mahmud Marzuki, Op. Cit., hal.134.

14) Peter Mahmud Marzuki, Penelitian Hukum, Cetakan ke-7. (Jakarta: Prenadamedia Group, 2011), hal. 177.

15) Jujun S.Suriasumantri, Filsafat Ilmu, Cetakan ke-3. (Jakarta: Pustaka Sinar Harapan, 1987), hal. 44 . 
deduktif berawal dari peraturan perundang-undangan yang bersifat umum, kemudian ditarik kesimpulan yang bersifat khusus, yaitu mengenai akibat hukum notaris yang mendirikan kantor cabang selama masa cuti.

\section{PEMBAHASAN}

\section{A. Kasus Posisi}

Kasus Di Indonesia notaris mempunyaii peranaan yng sangatt pentiing bagi masyarakat. Hal ini notaris sangat dibutuhkan mulai dari pendirian PT, membuat akta, legalisasi dokumen, waarmerking, dan jasa lain. Tidak hanya dalam bisnis tetapi juga untuk kebutuhan yang bersifat pribadi seperti membuat akta waris, akta hibah, balik nama sertifikat, pengecekan sertifikat tanah serta lainya. Hal ini membuat notaris sangat diperlukan bagi seluruh masyarakat di Indonesia. Pada Pasall 15 Ayt (1) Undaang-Unang Nomr 2 tahn 2014 tntang Jabattan Notariis. Notairis mempunyaii wewnang membuatt aktta otentiik mengenaii semua perbuattan, perjanjiian, dan penetpan yng diiharuskan oleh peratran perundaang-undanagan dan/atau yang dikehendakii oleh yang berkepentiingan untuk diinyatakan dlam akta otentiik, menjamin kepastiian tnggal pmbuatan aktaa, menyiimpan akta, memberiikan grose, saliinan dan kutiipan akta, semuaanya iitu sepaanjang pembatan aktta itiu tidiak juga diotugaskan atau dgikecualikan kepfada pejcabat laiin atau oraang laiin yang diitetapkan oleh undaang-undaang.

Akan tetapi dalam Putusan Nomor 2/PTS/Mj.PWN.Prov.DKIJakarta/ XI/2017 dalam perkara antara Majelis Pengawas Daerah Notari Kota Jakarta Barat melawan Netty Maria Machdar, S.H. Hal ini Merupakan putusan akibat seorang Notaris yang membuka kantor cabang.

Kasus tersebut terjadi pada saat Majelis Pengawas Notaris mendapati adanya satu Kantor Notaris dengan mempunyai 2 (dua) papan nama yaitu di Komplek Perkantoran Harmoni Mas Jl. Kunir Blok A/3 dan di Jalan Kembangan nomer 72 Jakarta Barat, kemudian terjadinya pemerikasaan terhadap Notaris Netty Maria Machdar S.H dengan Nomor : 
UM.MPDNJAKBAR.10.16 - 188 tanggal 31 Oktober 2016 dan bersama Notaris Pengganti yang bernama Jonni Tambunan, S.H, M.H, M.Kn bahwa Jonni selaku notaris pengganti. Di dalam jalannya persidangan Sidang Majelis Pengawas Daerah Notaris Jakarta Barat secara tertutup dimulai pada jam 13.00 WIB, disamping dihadiri oleh Notaris Netty Maria Machdar,S.H dan penggantinya yaitu Sdr. Jonni Tambunan, S.H, M.H, M.kn juga dihadiri oleh Majelis Pengawas Daerah Notaris Jakarta Barat Lainnya. Setelah menyampaikan keterangan tentang Hak dan Kewenangan yang dimiliki Majelis Pengawas Daerah Notaris Jakarta Barat, Ketua Sidang mengajukan pertanyaan mengapa ada pemasangan papan Notaris yang sama tetapi di tempat lain yaitu papan nama di Jalan Kembangan nomer 72 Jakarta Barat. Telepon : 021684441234 dan papan nama Netty Maria Machdar S.H. Komplek Perkantoran Harmoni Mas Jl. Kunir Blok A/3 Telepon 021 684441234, Lalu Notaris tersebut dengan kepercayaan diri yang sangat tinggi ia menjawab bahwa "karena Saya telah mendapat SK Menterii Hkum Dan Hak Asasii Manusiia Republiik Indonesiia, sebagai Notaris Pengganti, maka menurut Prof $\mathrm{X}$ saya berhak membuat papan nama tersendiri. Kemudian Ketua Sidang menyampaikan kepada Notaris Pengganti tersebut, "bahwa kita tidak memerlukan pendapat dari seorang professor atau siapapun juga ketika isi dari suatu pasal Undang-Undang sudah cukup dinyatakan jelas, sehingga tidakan memasang papan nama Notaris sebagaimana tersebut diatas sudah dalam kategori melanggar UndaangUndaang Nmor 2 Tahuun 2014 tntang Perrubahan atass Undaang-Undaang Nomoor 30 Thun 2004 tntang Jaabatan Notariis tertuang sebagaimana dimaksud dlam Pasal 19 ayat (1) yang berbunyii "Notariis wajiib mempunyaii hanyaa satuu kantorr, yaiitu tempatt keddukannya". Yaitu dianggap telah membuka cabang. Kemudian Ketua Sidang dngan terlebiih dahuulu memiinta persetujuan darii segenap anggota majelis Pengawas Daerah Notaris Jakarta Barat yang hadir meminta agar kepada Notaris Pengganti segera menurunka salah 1 (satu) diantara 2 (dua) papan nama 
tersebut diatas, dan langsung dijawab oleh mereka "kami akan merundingkan terlebih dahulu".

\section{B. Fakta Hukum}

Selain hal-hal yang telah diuraikan sebagaimana tersebut diatas, berikut ini disampaikan bahwa terdapat hal yang memberatkan bagi notaris Netty Maria Machdar, S.H. Untuk dipertimbangkan antara lain :

1. Pengaduan Pelapor telah cukup bukti

2. Berdasarkan Hasil Putusan Majelis Pengawas WilayahNotasis DKI Jakarta

Nomor: $\quad$ 05/PTS/Mj.PWN.Prov.DKI.Jakarta/VII/2015 Memutuskan "Menghukum Saudari Netty Maria Machdar, SH. Notaris di kota Administrasi Jakarta Barat dengan sanksi Teguran Tertulis";

3. Berdasarkan Berita Acara sidang MPDN Jakarta Barat Nomor: 1/BAP/LAMAS/2016 tanggal 3 Febuari 2016 perihal Berita Acara Pemeriksaan Notaris yang telah di sampaikan kepada MPWN DKI Jakarta UM.MPDN JAKBAR.03.16-83 tertanggal 31 Maret 2016. Bahwa Notaris yang bersangkutan diusulkan untuk diberikan saksi berupa Pemberhentian Sementara darii jabatannya sebagaii Notariis;

4. Bahwa pembuattan aktta yng telah dilakukan oleh Netty Maria Machdar, SH telah bertentangan dengan Undng-undng Nomr. 30 Thun 2004 juncto Undng-Undng No. 2 Thun 2014 tntang Jaabatan Notariis Pasal 16 ayat (1), dan Pasal 19 ayat (1).

5. Oleh karena terhadap Notaris Pengganti juga berlaku ketentuan dalam Pasal 4, 15, 16, dan pasal 17 Undaang-undaang Jabattan Notariis, maka semestinya terhadap Notariis Pengganti dalam hal ini Saudara Notaris Pengganti juga dikenai sanksi pengganti sebagaimana notaris yang digantikan terlebih sampai dengan ditandatanganinya Berita Acara ini tidak bersedia mencopot plang nama Notaris yang berada diluar kantor Notaris yang digantikannya. 


\section{Pertimbangan Majelis}

Menimbang :

1. Bahwa suratt pengaaduan Pelaport adlah sepertii tersbut diiatas;

2. Bahwaa Plapor merasa dirugikan oleh tindakan Terlapor yang telah melanggar Undng-Undng Nomr. 30 Tahunn 2004 tentng Jbatan Notariis juncto Undng-Undaang Nomr.2 2014 tntang Perbahan Atas UndngUndng Nomr 30 Taahun 2004 tntang Jbatan Notariis;

3. Bahwa Pelapor mendalilkan dalam pengaduannya bahwa Terlapor telah melanggar Undang-Undang Nomor. 30 Tahun 2004 tentang Jabatan Notaris juncto Undang-Undang Nomor. 2 Tahun 2014 tentang Jabatan Notaris maka yang demikian bisa mendapatkan sanksi sesuai hukum yang berlaku;

4. Bahwa Pelapor dapat membuktikan dalil Pelapor;

5. Bahwa pengaduan yang diajukan oleh Pelapor sudah sesuai dengan Peraturan Menteri Hukum dan Hak Asasi Manusia Nomor : M.02.PR.08.10.Tahun 2004;

6. Bahwa Pelapor telah beberapa kali mendapatkan sanksi teguran dari tertulis dari Majelis Pengawas Wilayah Daerah Notaris Provinsi DKI Jakarta;

Bahwa pihak Terlapor telah diperiksa oleh Majelis Pengawas Daerah Notaris Kota Administrasi Jakarta Barat dan dituangkan dalam Surat Memperhatikan :

1. Undang - Undang Nomor.30 Tahun 2004 tentang Jabatan Notaris juncto Umdang - Undang Nomor. 2 Tahun 2014 tentang Jabatan Notaris.

2. Peraturan Menteri Hukum dan Hak Asasi Manusia Republik Indonesia Nomor : M.02.PR.08.10 Tahun 2004 tentang Tata Cara Pemeriksaan Majelis Pengawas Notaris.

\section{Pemeriksaan di Majelis Pengawas Daerah Jakarta Barat}


Pada tanggal 13 Januari 2016 Majelis Pengawas Daerah Notaris Jakarta Barat melakukan pemeriksaan kekantor Terlapor.Pada tanggal 02 Februari 2016 Majelis Pengawas Daerah Notaris Jakarta Barat sudah mengirimkan surat pemberitahuan dan pemanggilan tentang akan dilakukannya pemeriksaan terhadap Notaris Netty Maria Machdar, S.H dan Notaris Penggantinya yaitu Sdr. Jonni Tambunan, S.H, M.H, M.Kn pada tangga 03 Februari 2016.

Majelis Pengawas Daerah Notaris Jakarta Barat sudah melakukan sidang tertutup dimulai pada pukul 13.00 Wib. Yang di hadiri oleh Notaris Netty Maria Machdar S.H dan Notaris Penggantinya yaitu Sdr. Jonni Tambunan S.H, M.H, M.Kn juga kepada anggota Majelis Pengawas Daerah Notaris Jakarta Barat lainnya.

E. Hasil Putusan Majelis Pemeriksa Wilayah (MPW) Notaris Provinsi Daerah Khusus Ibukota mengusulkan kepada Majelis Pengawas Pusat (MPP)

Ketua Majeliis Pengaawas Daeerah Notaris Kota Administrasi Jaakarta Barat Nomor : UM.MPDN JAKBAR.10.16 - 188 perihal Penyampaian Hasil Berita Acara Pemeriksaan Notaris Netty Maria Machdar, S.H. Bahwa hasil sidang Majelis Pemrksa Wilyh Notari Provinsi DKI Jakarta pada hari Selasa, tgll 16 Mei 2017 yang sudah kuorum karena dihadiri oleh tiga unsur anggota Majelis Pemerksa Wilyah Notris Provnsi DKI Jakarta dn sudah di putuskan beberapa hal yaitu : Pengaduan Pelapor telah cukup bukti. Terlapor telah melanggar Unddang-Udang Nmor 2 Thun 2014 tntng Perubhan Ats Unndang-Udang Nmor 30 Thun 2004 tntng Jabatan Notaris Pasal 19 ayat (1) Mengusulkan Pemberhentian Dengan Hormat Notaris Netty Maria Machdar dri jbatannya sbgai Notari.

\section{F. Larangan Notari Dlm Undang-Undang}


Pada UUJN telah diatur larangan yang telah ditetapkan yang terdapat pada Pasal 17 yang mengatakan bahwa ${ }^{16}$ Notari dilrang: Mnjalankan jbatan di luar wlyah jbtannya, Mnngglkan wlyah jabtannya leebih darri 7 (tjuh) hari kerja beturt-trut tnpa alsan yg sah, Meraangkap sbgai pgawai negri, Mrngkap jbatan sbgai pejaabat ne,gara, Merangkapp jabatn sbaagai advokat, Merangkap jabatan sebagai pemmpin ata pegwai bdn usha mlik ngara, bdan usha mlik daerh atau badan usha swasta, Merangkap jabatan sebagai Pejabat Pembuat Akta Tanah dan/atau Pejbat Lelang Kelas II di luar tmpat kedudukan notaris, Menjadi Notaris Pengganti; atau Melakukan pekrjaan lain yg bertentangan dgn norma agama, kesusilaan, atau keptutan yg dpt mempengaruhii kehoormatan daan martabak jabatagn notariis.

Notari yg melnggar ketntuan sebgaimana dimaksd pda ayat (1) dapt dikenai sanksi berupa Peringatan tertulis, Pembrhentian sementar, Pembrhentian dengn hrmat, atau Pemberhntian dngan tidk hrmat.

\section{G. Tmpat Keduudukan, Farmasi dan Wilyah Jabtan Notari}

Menurut Paasal 19 Undang-Udang No 2 Thun 2014 tentag Jbatan Notari mengtakan bawa ${ }^{17}$ : Notari wjib mmpunyai hnya satu kantor, yaitu di tmpat kedduknnya, Tempt kdudukan notari sebgai Pejabatan Pembuata Aktaa Tanaah wajiib meengikuti temmpat keddukan notari, Notariis tidakk berweanang secaara berturuta-turut dengaan tetaap menjalaankan jaabatan diluaar tempaat keddukannya, Notaris yng melanggar ketntuan sebgaimana dimksud paa ayat (2) dpt dikenai sanksi berupa: Peringatan tertulis, Pmberhentian semntara, Pembrhentian dgn hormat, atau Pmberhentian degan tidaak hormaat, Menurut Pasaal 20 Undaang-Udang Nmor 2 Tahun 2014 tentaang Jabaatan Notaaris mengatakaan baahwa ${ }^{18}$ :

\footnotetext{
16) Indonesia, Undang-Udang Nomor 2 Tahn 2014 tentang Jaabatan Notaaris, hal. 11.

17) Indonesia, Undang-Udang Nomor 2 Tahn 2014 tentang Jabaatan Notaaris, hal. 12.

${ }^{18)}$ Indonesia, Undang-Udang Nomor 2 Tahun 2014 tentang Jabataan Notaaris, hal. 13.
} 
1. Notari daapat menjaalankan jabataannya dalaam bentuk persekutuan perdata dengan tetap memperhatikan kemandirian dan ketidakpihakan dalam menjalankan jabatannya. a

2. Bentuk persekutuan perdata sebagaimana dimaksud pada ayat (1) diatur oleh para Notaris berdasarkan ketentuan perundang-undangan.

3. Dihapus

Menuruut Pasal 22 Unndang-Unddang Nommor 2 Thun 2014 tntang Jabatn Notari mengatakaan baahwa ${ }^{19}$ :

1. Formasi Jabaatan Notari ditetaapkan berdasaarkan: Kegiataan duniaa usaaha, Jumlaah penduduk, dan/atau Rata-rata jumlaah aktaa yaang dibuaat oleh dan/atau dihadaapan notaaris setiap bulaan.

2. Formasi Jabatan Notari sebgaimana dimksud pda ayat (1) meruppakan pedoman unutk menentukan kategori daerah.

3. Ketentuaan lebih laanjut mengenaai Formasi Jaabatan Notari daan penentuaann kategoori daaerah sebagaimana dimaksud pada ayat (1) dan ayat (2) diatur dgn peraturan Mentri.

\section{H. Kodee Eetik Notaaris Ikaatan Nootaris Inndonesia}

Setiap Notari dan orng laain yaang memaangku daan menjaalankan tugaas jabaatan notaaris oleh Paasal 3 diwaajibkan untuk ${ }^{20}$ : Memiliki mrral, akhlaak sertaa kepribaadian yang baik, Menghormati dan membela kehormatan perkumpulan, Menjaga dan membela kehormatan perkumpulan, Bertindak jujur, mandiri, tidak berpihak, penuh rasa tanggung jawab, berdasarkan peraturan perundang-undaangan dan isi sumpah jbatan notari, Meningkaatkan ilmu pengetahuan yang telah dimiliki tidak terbatas pada ilmu pengetahuaan hukum daan kenotariatan, Mengutamaakan pengabdian kepada kepentingan masyarakat dan neegara, Memberikaan jasaa

\footnotetext{
19) Ibid., hal. 13

20) Jimly Asshiddiqie, Peradilan Etik dan Etika Konstitusi. (Jakarta: Sinar Grafika, 2006), hal.
} $182-184$ 
pembuaatan aktaa dan jaasa kenotarisaan lainnya untuuk msyarakat yg tdak mmpu tnpa mmungut honrarium, Mentapkan satu kntor di tpt keddukan dan kntor tersbut merupkan satu-sattunya kantor bagi notari yg bersangkutan dalam melaksanakan tugas jabatan sehari-hari, Memasang 1 (satu) buah papannama di depan atau di lingkungan kantornya dengan pilihan ukuran yaitu $100 \mathrm{c}$ X 40cm, $150 \mathrm{~cm}$ X $60 \mathrm{~cm}$ atau $200 \mathrm{~cm} 0$ X $80 \mathrm{~cm}$, Hdir, mngikuti dan berprtisipasi aktif dlm setip kegiatn yg di selenggarakan olh perkumpulan; menghormatii; mematuhii; melaksanakn setiap dan seluruh keputusan perkumpulan, Membayar uang iuran perkumpuln scara tertib, Membyar uang duka utuk mmbantu ahli waris tman sejawat yng meninggal dunia.

Melksanakan dan mmatuhi semua ketentuan tntang honorarium ditetapkan oleh perkmpulan, Menjlankan jabatan notari terutma dlam pembuatan, pmbacaan dan penandatangan akta dilakukan dikantornya, kecuali alasan-alsan yng sah, Menciptakan suasana kekeluargaan dan kebersamaan dlm melksankan tugas dlm jbatan dan kegiatan sehari-hari serta saling mmperlkukan rekan sejawat scra baik, saling menghormati, saling menghargai, saling membantu serta selalu berusaha menjalin komunikasi dan tali silahturahmi, Memperlakukan setiap klien yng dtang dengn baik, tidk mmbedakan status ekonomi dan/atau status sosialnya, Melakukan perbuatan-perbuatn yangg secaraa umum di sebut sebagai kewajiban untuk ditaati dan dilaksanakan antaraa lain namun tidak terbatas pada ketentuan yang tercantum dalaam:

1. UU Nomor 30 Tahunn 2004 ttentang Jabatan Notaris;

2. Penjelasan Pasal 19 Ayat (2) UU Nomor 30 Tahun 2004 tentang Jabatan Notariss;

3. Isi sumpah jabatann notariss;

4. Anggaran dasarr dan Anggaran Rumah Tangga Ikatan Notaris Indonesiia. 
Kepadaa setiap notaris dann pelaku tugas jabatan notariss lainnya, berdasarkan Pasal 4 ditentukan laranganlarangan sbagai berikut ${ }^{21}$ : Mempunyai lebih dari 1 (satu) kntor, baik kntor cabang ataupun kantor perwakilan. Memasang papan nama dan/atau tulisan yng berbunyi Notaris atau Kantor Notaris diluar lingkungn kantor. Melkukan publikasi atau promosii diri, baik sndiri maupun bersam-sama, dngan mencantumkan nama dan jbatannya, menggunakan srana media cetak dan/atau elektronik dlam bentuk yaitu iklan, ucapan selamat, ucpan belasungkawa, ucapan trima kasih, kegiatn pemasaran, kegiatn sponsor, baik dlam bidng sosial keagaman, maupun olahrga. Bekerjsama dngan Biro Jasa / orng / Badan Hkum yangg padaa hakekatnya bertindak sebagaii perantara unntuk mencarii atau mendapatkan klien.

Menandatanganii akta yang prosess pembuatan minutanya telah dipersilakan oleh pihak laain. Mengirimkan minuta kepada klien untukk ditandatangani. Berusaha atau berupaya dngan jalan apapunn, agar sseorang berpindah dari notaris lain kepadany, baik upaya itu ditnjukan langsung kepada klien yng bersngkutan maupun melalui prantara orng lain. Melakukan pemksaan kepda klien dngn cara mnahan dokumendokumen yangg telahh diserahkan dan/atau melakukann tekanan psikologis dengan maksud agar klien tersebut tetap membuat akta padanya.Melakukan usahausaha, baik langsung maupun tdk langsung yg menjurus kearah timbulnya persaingan yg tdk sehat dengann sesamaa rekan notaris.

Menetapkan honorarium yg harus dibyar oleh klien dlm jumlah yang lebih rendah dari honorarium yg telah ditetapkan oleh perkumpulan. Memperkerjkan dgn sengaja orng masiih berstatus karyawan kantorr notariss lain tanpa persetujuan terlebih ddahulu dari notariss yangg bersangkutan. Menjelekan dan/atau mempeersalahkan rekan notariis atau akta yang dbuat

21) Ibid,. Hal. 184-185 
olehny. Dlam halseorang notari menghdapi dan/atau mnemuikan suatu akta yangg dibuat oleh rekan sejawat yang ternyta didalmnya terdapat kesalahankesalahan serius dan/atau membahayakn klien, maka notari trsebut wajib mmberitahukan kepda rekan sejawat yang bersangkutn atas kesalahn yangdibuatnya dengn cara yng tidak bersifat mennggurui, melainkan untu mencegh timbulnya hal-hal yang tdak diinginkan terhadap klien yang brsangkutan ataupun rekan sejawat trsebut.

Membntuk kelompok sesama rekan sejawatyang bersifat eksklusif dngan tujuan utuk melyani kepntingan suatu instansi, apalgi mentup kmungkinan bagi notaris lain untk brpartisipasi. Menggunakaan daan mencantumkaan gelaar yaang tidaak sesuaai dengaan peraaturan perundaang-undngan yaang berlaaku. Melaakukan perbuatanperbuaatan lain yaang secaara umum disebut sebaagai pelanggaaran terhaadap kode etik notariss, antara laain namun tidaak terbataas padaa pelanggaranpelaanggaran terhaadap:

1. Ketentuan-ketentuaan daalam Undang-Undang Nomor 30 Tahun 2004;

2. Penjelasan Pasal 19 Ayat (2) Undaang-Undang Nomor 30 Taahun 2004 tentaang Jaabatan Notariss;

3. Isi sumpaah Jabatann Nootaris;

4. Haal-hal yangg menurut aanggaran dasaar, anggaraan rumahtangga dan/atau kputusan-keputsan lain yang tlah ditetpkan oleh orgnisasi Ikaatan Notari Indonesiaa (INI) tidak boleh dilaakukan oleh aanggota.

Yaang secaraa tegaas boleh dikecualikan daari laarangan tersebut diatas, sehinggaa tidaak termasuk dalaam pengertian pelanggran, menurut keetentuan Pasal 5, hanyalah halhal sebagaii berikutt ${ }^{22}$ : Memberikanucapan selamat, ucapan berdukacita dngan mempergunkan krtu ucapn, surat, karangn bunga, atapun media lainya yang tidakk mencantumkkan notari,

${ }^{22)}$ Ibid,. Hal. 186. 
tetapii hanyaa mencaantumkan naama saaja. Pemuataan namaa daan alaamat notariis dal am buku panduann teelepon, fax, telex, yang diiterbitkan secaraa resmi olehPT. Telkom dan/atau instansinstansi dan/atau lembagaembaga resmi lainnyaa. Memasang 1 (satu) taanda penunjauk jalaan dengaan ukuraan tidaak melebihi $20 \mathrm{~cm} \mathrm{X} 50$ cam, dasar berwarnaputih, hurfu aberwarna hiatm tanpa mencantumkan nama notari serta dipsang dalaam raadius maksmum $100 \mathrm{~m}$ dar i kantor notaris.

Pada Pasal 6 kode etik, diatur tentang sanksi terhadap pelanggaran kode etik, dikenakan beberapa kemungkinan sanksi yaitu ${ }^{23}$ : Teguran, Peringatan, Schorsing (pemecatan sementara) dari keanggotaan perkumpulan, Anzetting (pemecatan) dari keanggotaan perkumpulan, Pemberhentian dengan tidak hormat dari keanggotaan perkumpulan.

Penjatuhan sanksi-sanksi sebagaimana tersebut diatas terhadap anggota yang melanggar kode etik disesuaikan dengan kuantitas dan kualitas pelanggaran yang dilakukaan anggota tersebut. Jika, misaalnya, suatu pelanggaran - meskipun bersifat ringan - telah dilakukan secara berulangulang, maka terhadapnya dapat saja dijatuhkan sanksi yang sifatnya lebih berat daripada kualitas pelanggaran nya.

\section{Prosedur Penegakan Kode Etik Ikatan Notaris Indonesia}

Pasal 8 menentukan bahwa Dewann Kehormataan merupkan alat perlengkapanPerkumpulan yng berwenanmg melakkukan pemeriksaan atas pelanggaran terhaadap kode etik dan men jatuhkan sanksi kepada pelaanggarnya sesuai dengan kewenangaan masingmasing. Pemeriksaan dan penjatuhan sanksi pada tingkat pertama diatur pda Pasal 9 yang menentukan sebagai berikut ${ }^{24}$ :

1. Apabilaa ada anggotaa yang di duga mellakukan pelanggarn terhdap kodde etik, baik dufgaan teersebut berasasl dari pengetahuasn Dewan 
Kehormatan Daerah sendiroi maupun karna laporan dari Pengurus Daerah ataupun pihak lain kepada Dewan Kehormatan Daerah, maka selambat-lambatnya dalam waktu tujuh (7) hari kerja Dewan Kehormatan Daerah wajib segera mengambil tindakan dengan mengadakan siding Dewan Kehormatan Daerah untk membicarkan dugan pelanggaan tersbut.

2. Apabila menrut hasil siding Dewan Kehormatan Daerah sebagaimana yang tercantum dlam ayat (1), trnyata ada dugaan kuat terhdap pelangaran kode etik, maka dlam waktu tjuh (7) hari kerja setelah tanggal siding tersebut, Dewan Kehormatan Daerah berkerwajiban memanggil anggota yang diduga bersalah tersebut dngan surat tercatat atau dengan ekpedisi, untuk didengar keterangannya dan diberi kesempatan untuk membela diri.

3. Dewan Kehormatan Daerah baru akan menentukan putusannya mengenai terbukti atau tidaknya pelanggaran kode etik serta penjatuhan sanksi terhadap pelanggarnya (apabila terbukti), setelah mendengar keterangan dan pembelaan diri dari anggota yang bersangkutan dalam siding Dewan Kehormatan Daerah yang diadakan untuk keperluan itu, dengan pengecualian sebagaimana yang diatur dalam ayat (6) dari ayat (7) pasal ini.

4. Penentuan putusan tersebut dalam ayat (3) di atas dapat dilakukan oleh Dewan Kehormatan Daerah, baik dalam siding itu maupun siding lainnya, sepanjang penentuan keputusan melanggar atau tidak melanggar tersebut dilakukan selambat-lambatnya dalam waktu 15 (lima belas) hari kerja, setelah tanggal sidang Dewan Kehormatan Daerah di mana Notaris tersebut telah didengar keterangan dan/atau pembelaannya. 
5. Bila dalam putusan siding Dewan Kehormatan Daerah dinyatakan terbukti ada pelanggaran terhadap kode etik, maka siding sekaligus menentukann sanksi terhadap pelanggarannya.

6. Dalam hal anggota yng dipanggil tdak dating atau tidak memberi kabar apapun dalam wktu 7 (tujuh) hari kerja setelah dipanggil, maka Dewan Kehormatan Daerah akn mengulangi penggilannya sebanyak 2 (dua) kali dengn jarak waktu 7 (tujuh) hari kerjaa, untuuk setiap panggila.

7. Dalam waktu tujuh (7) hari kerja, setelah panggilan kerja (3) ternyata masih tdak dating atau tidk memberi kabar dngan alasan apa pun, maka Deewan Kehormatan Daeerah akan tetap bersidaang ntuk membicarakan pelanggaraan yaang diduga dilakukan oleh anggota yang dipanggil itu dan meanentukan putusaannya, seelanjutnya secaraa mutatis mutandis berleaku ketentauan dalam ayat (5) dan ayat (6) di atas serta ayat (9).

8. Terhadap saanksi pemberheentian seementara (schorsing) ataau pemecatan (onzetting) dari keeanggotan peerkumpulan diputuskaan, Dewan Kehormaatan Daerah wajib berkonsuletasi terlebih daahulu dengan Peengurus Daeraahnya

9. Putusan siding Dewan Kehornatan Daerah kepada anggota yang melanggar dengan surat tercatat atau dengan ekspedisi dan tembusannya kepada Pengurus Cabang, Pengurus Daerah, Pengurus Pusat dan Dewan Kehormatan Pusat, semuanya itu dalam waktu tujuh (7) hari kerja, setelah dijatuhkan putusan oleh siding Dewan Kehormatan Daerah.

10. Apabila pada tingkat kepengurusan Daerah belum dibentuk Dewan Kehormatan Daerah, maka Dewan Kehormatan Wilayah berkewajiban dan mempunyaai weweenang untuk meenjalankan kewajiban serta keweenangan Dewaan Kehormatann Daerah daalam rangka peneegakan Kode Etk atau melimpahkamn tugas kewajibaan dan keewenangan Dewan Kehormatean Daerah kepada Kwenangan Dewa Kehormatan Daerah terdekat dari tmpat kedudukan atau tempt tinggail anggopta 
yangh melanggar kode etik tersebu,t. Hal tersebuttt berlakuk pulak apabila Dewa Kehpormatan Daerah tidk snggup menyelsaikan atau mmutuskan permasalahn yang dihadaepinya. Pemeriksaan dan Penjatuhan Sanksie.

Sedangkain pemeriksaman dan penjatuhan sanksi pada tingkat akhir diatur pada Pasal 11 yang menentukan sebagai berikut ${ }^{25}$ : Putusan yng berisi penjatuhaan sanksi pemecataan sementaraa (schorsing) atau pemeecatan (onzetting) dari keanggootan perkumpuulan yng dilakukaan oleeh Dewan Kehormayan Wilatyah daapat diajukean/dimohonkan. pemerikasaan pada tingkat teraakhir keepada Dewan Kehormatan Pusaat. Permohonan unutk pemeriksaaan tingkat akhir waejib dilakukan oleh anggota yag bersangkutan dalaam waktu tigaa puluhj (30) hari kerja, setelah taanggal penerimaaan suraat putusan peenjatuhan sanksi dari Deewan Kehormaatan Wilayaah.

Permohonaan peameriksaan tingkat akhir dikirim denagan suraat tercatat aatau melalui ekspeedisi atau oleh anaggota yang bersangkutaan kepadaa Dewan Kehormeatan Pusat dan tembusannyea kepaada Dewa Kehormaatan Daeerah, Pengurus Puesat, Pengureus Wilayah dan Peengurus Daeraah. Dewa Kehormatan Wlayah dlam waktu tuuh (7) hari stelah menerima surat tembusan permhonan pemerikaan tingkat terakhiir wajnib mengrim semua salinann/ fotocopy bekas pemriksaan Dewa Kehormtan Pust. Stelah mnerima permohnan pemeriksan tingkat teakhir, Dewn Kehrmatan Pusat wjib memnggil anggota yng meminta pemerksaan tersebut, slambat-lambatny dalamn waktui tiga pulh (30) hari kerja, setelaah meneerima permohnan pemeriksaan tersebut, dpanggil, didngar keterangannya dan diberii kesempaatan untuk membelaa diri dalaam siding Dewn Kehomatan Pusat.

25) Ibid., Hal. 190-191. 
Dewn Kehormaataan Pusaat wajib memberi putusaan dalaam pemeiksaaan tingkati terakhir melaalui sidaangnya, dalaam waktu tigaa puluh (30) hari kerja, setelaah anggota yanag bersaangkutan dpanggil, didengar keteraangannya dan diberi kesempataan untuk membla diri. Apabilaa anggota yaang dipaanggil tidak dating dan tidak memberi kaabar dengan alasan yng sah melaalui surat tercatat, mka siding Dwan Kehormatan Pusat tetaap akan memberi putusan dlam waktu yang ditentukan padaa ayat (5) di atas. Dwan Kehormatan Wilyah Pusat wajib mengirim ptusannya kepada anggotaa yang minta pemeriksaaan tingkat teraakhir dengan surat tercatat atau dengan ekspedisi dan tembusaannya kepda Dewan Kehormatan Daerah, Pengurus Cabang, Pengurus Daerah dan Pengurus Pusat, semuanya itu dalam waktu tujh (7) hari kerja, seteleh siding Drwan Kehormatan Pusat menjqtuhkan keputusannya atas pemeriksaan tingkat terkahir terswbut.

\section{J. Akibat Hukum Yang Ditimbulkan Dari Notaris Netty Maria Machdar Yang Mendirikan Kantor Cabang Dengan Namanya Sendiri}

Kunsep tanggungg jawqb hkum berkaitaan erat dengqn konsrp hak dan kewajban. Kansep yang menekannkan paada pengertian hak yng berpasangan dngan pengeertian kewajiban. ${ }^{26}$ Pendapqt yanh umunm mengatakan bahjwa hak pada seseorag senantiasa berkolerasi degnan kewajian pada orang lain. ${ }^{27}$ Akibat hukum yang ditimbul dari Notaris Netty Maria Machdar yang mendirikan kantor cabang dengan namanya sendiri yang telah melanggar Pasal 19 UUJN yang mengatakan ${ }^{28}$ : Notari wajb mempunyyai haya satu kantoor, yaitu di tempqt kediduknnya. Tempat kedudukqn notaris sebagai Pejabatan Pembuat Akta Tqnah wajib mengikut temp4t kedudukan notari. Notqris tidak berweenang seecara berturut-urut dengan tetaap menjalankan jaabatan diluar tempat kedudukaannya. Notaris

\footnotetext{
26) Satjipto Rahardjo, Ilmu Hukum, (Bandung: PT Citra Aditya Bakti, 2000), hal. 55.

27) Ibid, hal. 57.

28) Indonesia, Undang-Undang Nomor 2 Tahun 2014 tentang Jabatan Notaris, hal. 12.
} 
yang melangggar ketentuan sebageimana dimaksudi padah ayat (2) dapaty dikenai sanksi berupa: Peringatan tertulis, Pemberhentian sementara, Pemberhentian drngan ormat, atau Pembeerhentian dengan tidqk howrmat.

Tetapi tidak hanya diusulkan untuk diberhentikan dengan hormat yang tredapat pada Putusn Nomor: 2/PTS/Mj.PWN.ProvDKIJakarta/ix/2017. Tetapii Notaris Netty Machdar juga telah melanggar Kode Etik Ikatan Notarie Indomnesia pada Pasal4 ayat (a) dan pasal 4 ayat (b) yang mengatakan bahwa ${ }^{29}$ : Mempunyqi lebih dasri 1 (satu) kator, baik kntor cabawng atauipun kantor perwakikilan dan memasang papan nama dan/atau tulisan yang berbunyi Notars atu Kanor Noaris diluar lngkungan kntor.

Pada pelangaran yag dilangar oleh Notari Netty Maria Machdar yang trdapat pada Kode Etik Iktan Notaris Indonesia trdapat juga sanksi yang telah diatur pda Pasal 6 Kode Etik yaitu: Teguuran, Peringaatan, Schorsing (Pemecatan Seentara) dari keanggotaan Perkumpulan, Onzetting (Pemecatan) dri Keanggotan Perkumpuln, Pemberhentian dngan tidak hormat dari Keanggotan Perkumpulaan.

Penjatuhan sanki-sanksi sebagaaimana tesrebut di atas terhaadap anggota yang melangar Kode Etik disusuaikan dngan kuantitas dn kualitas pelanggaran yang dilqkukan angota tersebit. Jika misalnya, suatu pelanggaran - meskipun bersifat ringan - telah dilakukan secara berulangulang, maka terhadapnya dapat saja dijatuhkan sanksi yang sifatnya lebih berat daripada kualitas pelanggarannya. Sehingga penjatuhan sanksi ini terhadap notaris telah adanya pengaturan di setiap pasalnya. Karena Notaris Netty Maria Machdar telah terbukti melanggar Kode Etik Ikatan Indonesia.

Dalam hal ini, kerugian yang timbul akibat kesalahan Notaris Netty Maria Machdar juga harus dimintain ganti kerugian baik secara materiil dan non - materiil karena kerugian yang ditimbulkan cukup banyak dan dalam

29) Jimly Asshiddiqie, Peradilan Etik dan Etika Konstitusi. (Jakarta: Sinar Grafika, 2006), hal. 184. 
skala besar apabila dilihat dari putusan dan pemeriksaan yang dilakukan oleh Majelis Pemeriksa Wilayah.

\section{PENUTUP}

Berdasarkan Pokok Permasalahan yang digunakan, maka dapat disampaikan suatu kesimpulan dan saran sebagai berikut :

\section{A. Kesimpulan}

Berdasarkan pembahasan penelitian mengenai pelanggaran jabatan sebagai Notaris menurut Undng-Udang Jabqtan Notari (UUJN), maka penulis dpat menarikk kesimpulqn bqhwa Notaris Netty Maria Machdar terbukti bersalah karena telah merugikan masyarakat karena tidak menjalankan tugasnya sebagaimana Profesi yang luhur dan bermartabat.

Pertanggungjawaban yang dapat dilakukan oleh Netty Maria Machdar

menurut keputusan Majelis Pemeriksa Wilayah Notaris Provinsi Daerah Khusus Ibukota Tentang Laporan Pengaduan Masyarakat kepada Majelis Pengawas Daerah atas 2 (dua) papan yang telah mempunyai cukup bukti bahwa Netty Maria Machdar diusulkan untuk diberhentikan secara tidak hormat sebagai pertanggungjawaban atas perbuatannya yang telah terbukti bersalah karena dianggap telah merugikan masyarakat kepada Netty Maria Machdar.

Tetapi karena tidak cukup untuk Notaris tersebut hanya diberhentikan dari jabatannya. Maka penulis merasa Notaris Netty Maria Machdar juga perlu untuk mengganti kerugian secara materil dan non materil kepada pihak yang telah dirugikan. Disamping itu perlunya melihat dari sudut pandang Kode Etik yang telah dilanggar oleh Notaris Netty Maria Machdar karena Ia juga telah terbukti melangar Kodee Etik Ikatan Nptaris Indonesia yang terdapat pada pasal 4 yaitu membuka kantor cabang lebih dari satu. Karena telah ditentukan.

Notaris Netty Maria Machdar secara tidak langsung juga dapat dikenai sanksi hukuman penjara agar terdapat rasa jera atas perbuatan yang telah ia lakukan. Karena adanya unsur kesengajaan yang ditimbulkan olehnya dan 
juga Notaris Penggantinya. Sehingga Notaris Netty Maria Machdar dapat merenungkan perbuatan yang timbulkan, karena sangat merugikan pihakpihak yang bersangkutan serta masyarakat luas.

Kedudukan notaris menjadi menggantung dikarenakan belum adanya keputusan pasti dari Majelis Pengawas Pusat sehingga Notaris Netty Maria Machdar masih dapat menjalankan hak dan kewajibannya menjadi Notaris. Hal ini dapat menyebabkan akan banyaknya korban dari Notaris Netty Maria Machdar. Pada kasus ini juga adanya unsur kesengajaan karena Notaris tersebut juga dengan sengaja membuat kantor cabang padahal ia juga sedang berstatus cuti. Notaris Netty Maria machdar juga melanggar Kode Etik Ikatan Notaris Indonesia dikarenakan adanya Pasal 4 yang dilanggar oleh Netty Maria Machdar. Sehingga dalam hal ini Notaris Netty Maria machdar benarbenar terbukti bersalah. Dan harusnya dikenai sanksi hukuman penjara.

\section{B. Saran}

1. Kepada seluruh Notaris di Indonesia : semestinya setiap notaris di dalam menjalankn tuugas jabatanya hqrus dilandaskan pada integritas dan moralitas juga pemahaman tentang ilmu diluar ilmu kenotariatan sehingga masyarakat menganggap bahwa notaris bukanlah merupakan orang yang kurang akan pemahaman tentang pengetahuan dan pengalaman diluar tentang ilmu kenotariatan serta menerapkan prinsip tanggung jawab serta memahami ketentuan yang telah ditetapkan oleh UUJN, Kod Eik Noaris, dan perturan prundang-undagan lainnya. Diharapkan juga bahwa sumpah yang telah notaris jalankan dapat menjadi landasan pemikiran agar terhindar menjadi notaris "bandel", agar tidak menimbulkan kerugian kepada phak-pihak yang mersa dirugiikan, sehingga harus adanya pertanggungjawaban sesuai dengan ketentuan yang berlaku di dalam perauran prundang - undagan, UUJN dan Kode Etik Notaris.

2. Kepada MPD, MPW, MPP : Meningkatkan peranan sebagai Majealis Peangawas Daeriah, Wilayah dan Pusat agar semakin memperketat setiap 
apapun yang dilakukan notaris, sehingga setiap laporan bulanan yang dilaporkan oleh notaris kepada Majelis dapat diawasi dengan benar dan ketat.

3. Kepada Ikatang Notarias Indonisia (INI) dalam pelaksanaan pengaawsan notarias agar meminimalisirkan setiap notaris yang melanggar setiap peraturan yang telah di buat .

\section{DAFTAR PUSTAKA}

\section{A. BUKU}

A. Kohar, Notaris Dalam Praktek Hukum. (Bandung: Alumni, 1983)

Adjie, Habib., Hukum Notaris Indoensia Tafsir Tematik Terhadap UU No. 30 Tahun 2004 Tentang Jabatan Noataris. (Bandung: PT Refika Aditama, 2008),

Asshiddiqie,Jimly. Etik dan Etika Konstitusi Perspektif Baru Tentang ('Rule of Law and Rule of Ethics' \& Constitutional Law and Constitutional Ethics') edisi revisi. (Jakarta: Sinar Grafika, 2016).

Pengurus Pusat Ikatan Notaris Indonesia. Jati Diri Notaris Indonesia, Dulu, Sekarang dan di Masa Datang. (Jakarta: PT. Gramedia Pustaka, 2008).

Soemoatmodjo, Soetardjo. Apakah: Notaris, Pejabat Pembuat Akta Tanah dan Pejabat Lelang. (Yogyakarta: Liberty, 1986).

Soesanto. R., Tugas, Kewajiban, dan Hak-Hak Notaris, Wakil Notaris. (Jakarta: Pradnya Paramita, 1982)

Tedjosaputro, Liliana., Etika Profesi Notaris Dalam Penegakan Hukum Pidana. (Yogyakarta: Bayu Grafika, 1995

\section{B. PERATURAN PERUNDANG-UNDANGAN}

Indonesia. Undang-undang Nomor 2 Tahun 2014 tentang Jabatan Notaris 